\title{
NLRP3 inflammasome-dependent pyroptosis is proposed to be involved in the mechanism of age-dependent isoflurane-induced cognitive impairment
}

Lei $\mathrm{Yin}^{1,2}$, Fangping $\mathrm{Bao}^{3}$, Jing $\mathrm{Wu}^{4^{*}}$ and Kuanyu $\mathrm{Li}^{4^{*}}$

\begin{abstract}
Wang $Z$ et al. recently published a paper, titled "Critical role of NLRP3-caspase-1 pathway in age-dependent isoflurane-induced microglial inflammatory response and cognitive impairment". The finding in this paper is consistent with our previous study on NLRP3-caspase-1 pathway. Here, we propose that NLRP3 inflammasomedependent pyroptosis may be involved in the mechanism of age-dependent isoflurane-induced cognitive impairment and discuss that inhibiting NLRP3 inflammasome activation with a novel inhibitor MCC950 may ameliorate age-dependent isoflurane-induced neuro-inflammation.
\end{abstract}

Keywords: Isoflurane, Cognition, NLRP3, MCC950, Pyroptosis

Letter to the editor

Recently, we read with great interest the article titled "Critical role of NLRP3-caspase-1 pathway in agedependent isoflurane-induced microglial inflammatory response and cognitive impairment" by Dr. Wang Z et al. [1], who concluded that NLRP3 priming status in aged mouse brain may be involved in isoflurane-induced hippocampal inflammation and cognitive impairment. We appreciate this study and would like to present our opinion on it.

The NLRP3 inflammasome-caspase-1 pathway has been implicated in several metabolic and inflammatory diseases $[2,3]$. It is also proposed to be a possible pathogenic mechanism for general anesthesia-induced neuro-inflammation and cognitive impairment $[4,5]$. We have previously shown that isoflurane induces activation of NLRP3, cleavage of caspase 1 , and increase of IL- $1 \beta$ and TNF- $\alpha$ levels in the hippocampus of aging mice and supposed that inhibiting the NLRP3 inflammasome might have therapeutic merit for ameliorating general anesthesia-induced cognitive deficits [5] as cited in Wang's study. However, the selective inhibitor

\footnotetext{
* Correspondence: jing.wu@smail.nju.edu.cn; likuanyu@nju.edu.cn ${ }^{4}$ Jiangsu Key Laboratory of Molecular Medicine, Medical School of Nanjing University, Nanjing 2100093, China

Full list of author information is available at the end of the article
}

of NLRP3 inflammasome was lacking. Interestingly, in Wang's study, they demonstrated that treatment of Ac-YVAD-cmk, an inhibitor of NLRP3-caspase-1, reversed isoflurane-induced microglial inflammatory response and cognitive impairment in aged mice [1]. This finding is a very important evidence for supporting that NLRP3-caspase-1 pathway is involved in the mechanism of general anesthesia-induced cognitive impairment. However, Ac-YVAD-cmk is a specific inhibitor of caspase-1, not of NLRP3 inflammasome. It is uncertain whether cleavage of caspase-1 directly results from NLRP3 inflammasome activation and results in the secretion of the pro-inflammatory IL- $1 \beta$ and IL-18 in Wang's study $[1,6,7]$. The treatment of aging mice with NLRP3 inflammasome inhibitor will be needed. MCC950 is a highly potent specific NLRP3 inhibitor and was first introduced as a specific anti-inflammatory compound since 2015 [8]. The novel compound MCC950 has been clearly shown to be neuroprotective in multiple neurological disorders, including ischemic and degenerative diseases $[9,10]$. Although MCC950 has not been used in general anesthesia issues, we think that it is promising as a therapeutic compound for treatment of general anesthesia-induced neuro-inflammation and cognitive impairment. 
Pyroptosis is a novel inflammatory form of programmed cell death that has been discovered and verified recently. This type of cell death is characterized to be NLRP3 inflammoasome-caspase-1 dependent [11-13]. Recent advances strongly hint that pyroptosis plays a regulatory role in many infectious and noninfectious diseases [11], and MCC950 can inhibit NLRP3 inflammasome to further prevent pyroptosis [12]. However, little is known about the functions of pyroptosis in general anesthesia-induced neurotoxicity, and thus, an effective intervention, MCC 950, is emerging. Wang's study found that isoflurane activated NLRP3-caspase-1 pathway and increased the secretion of IL-18 and IL-1 $\beta$ in cells pretreated with lipopolysaccharide and suggested that isoflurane induces age-related hippocampal inflammation through NLRP3caspase-1 pathway. In this regard, we present a hypothesis that pyroptosis plays a critical role in the mechanism of isoflurane-induced cognitive impairment and MCC950 inhibits the NLRP3 inflammasome-dependent pyroptosis in isoflurane anesthesia to improve the cognition.

Collectively, we present our hypothesis that NLRP3 inflammasome-dependent pyroptosis may be involved in the mechanism of age-dependent isoflurane-induced cognitive impairment, and inhibition of the NLRP3 inflammasome activation with MCC950 may ameliorate age-dependent isoflurane-induced neuro-inflammation. Future studies are needed to confirm the hypothesis.

We again compliment the authors on their excellent article and thank them for their contribution to it.

\section{Abbreviations}

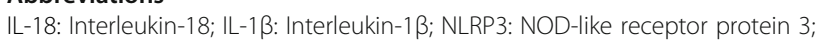
TNF-a: Tumor necrosis factor-a

\section{Availability of data and materials}

Data sharing is not applicable to this article as no datasets were generated or analyzed during the current study.

\section{Authors' contributions}

LY and JW wrote the first draft of the paper. FB and $\mathrm{KL}$ contributed to the writing of the paper. All authors read and approved the final manuscript.

\section{Ethics approval and consent to participate}

Not applicable.

Consent for publication

Not applicable.

\section{Competing interests}

The authors declare that they have no competing interests.

\section{Publisher's Note}

Springer Nature remains neutral with regard to jurisdictional claims in published maps and institutional affiliations.

\section{Author details}

'Department of Anesthesiology, Shanghai Pudong New Area People's Hospital, Shanghai 201200, China. 'Wannan Medical College, Anhui 241003, China. ${ }^{3}$ Department of Anesthesiology, The First Affiliated Hospital, College of Medicine, Zhejiang University, Hangzhou 310003, China. ${ }^{4}$ Jiangsu Key
Laboratory of Molecular Medicine, Medical School of Nanjing University, Nanjing 2100093, China.

Received: 24 April 2018 Accepted: 20 June 2018

Published online: 14 September 2018

\section{References}

1. Wang Z, Meng S, Cao L, Chen Y, Zuo Z, Peng S. Critical role of NLRP3-caspase1 pathway in age-dependent isoflurane-induced microglial inflammatory response and cognitive impairment. J Neuroinflammation. 2018;15:109.

2. Chen W, Foo SS, Zaid A, Teng TS, Herrero L, Wolf S, Tharmarajah K, Vu LD, van Vreden C, Taylor A, et al. Specific inhibition of NLRP3 in chikungunya disease reveals a role for inflammasomes in alphavirus-induced inflammation. Nat Microbiol. 2017;2:1435-45

3. Lee HJ, Hong YS, Jun W, Yang SJ. Nicotinamide riboside ameliorates hepatic metaflammation by modulating NLRP3 inflammasome in a rodent model of type 2 diabetes. J Med Food. 2015;18:1207-13.

4. Li XM, Zhou MT, Wang XM, Ji MH, Zhou ZQ, Yang JJ. Resveratrol pretreatment attenuates the isoflurane-induced cognitive impairment through its antiinflammation and -apoptosis actions in aged mice. J Mol Neurosci. 2014;52:286-93.

5. Wu J, Li H, Sun X, Zhang H, Hao S, Ji M, Yang J, Li K. A mitochondriontargeted antioxidant ameliorates isoflurane-induced cognitive deficits in aging mice. PLoS One. 2015;10:e0138256.

6. Wang L, Fu H, Nanayakkara G, Li Y, Shao Y, Johnson C, Cheng J, Yang WY, Yang $F$, Lavallee $M$, et al. Novel extracellular and nuclear caspase-1 and inflammasomes propagate inflammation and regulate gene expression: a comprehensive database mining study. J Hematol Oncol. 2016;9:122.

7. Rathinam VA, Fitzgerald KA. Inflammasome complexes: emerging mechanisms and effector functions. Cell. 2016;165:792-800.

8. Coll RC, Robertson AA, Chae JJ, Higgins SC, Munoz-Planillo R, Inserra MC, Vetter I, Dungan LS, Monks BG, Stutz A, et al. A small-molecule inhibitor of the NLRP3 inflammasome for the treatment of inflammatory diseases. Nat Med. 2015;21:248-55.

9. Qi Y, Klyubin I, Cuello AC, Rowan MJ. NLRP3-dependent synaptic plasticity deficit in an Alzheimer's disease amyloidosis model in vivo. Neurobiol Dis. 2018:114:24-30.

10. Ye X, Shen T, Hu J, Zhang L, Zhang Y, Bao L, Cui C, Jin G, Zan K, Zhang Z, et al. Purinergic $2 X 7$ receptor/NLRP3 pathway triggers neuronal apoptosis after ischemic stroke in the mouse. Exp Neurol. 2017;292:46-55.

11. Jiang $D L$, Chen S, Sun RY, Zhang X, Wang D. The NLRP3 inflammasome: role in metabolic disorders and regulation by metabolic pathways. Cancer Lett. 2018:419:8-19.

12. Dempsey C, Rubio Araiz A, Bryson K, Finucane O, Larkin C, Mills EL, Robertson AAB, Cooper MA, O'Neill LA, Lynch MA. Inhibiting the NLRP3 inflammasome with MCC950 promotes non-phlogistic clearance of amyloid-beta and cognitive function in APP/PS1 mice. Brain Behav Immun. 2017;61:306-16.

13. Wu DD, Pan PH, Liu B, Su XL, Zhang LM, Tan HY, Cao Z, Zhou ZR, Li HT, Li $\mathrm{HS}$, et al. Inhibition of alveolar macrophage pyroptosis reduces lipopolysaccharideinduced acute lung injury in mice. Chin Med J. 2015;128:2638-45.

Ready to submit your research? Choose BMC and benefit from:
- fast, convenient online submission
- thorough peer review by experienced researchers in your field
- rapid publication on acceptance
- support for research data, including large and complex data types
- gold Open Access which fosters wider collaboration and increased citations
- maximum visibility for your research: over 100M website views per year
At BMC, research is always in progress.
Learn more biomedcentral.com/submissions

